\title{
Chemoecological Study of Trophic Interaction Between Pseudosphinx Tetrio L. Larvae and Allamanda Cathartica L.
}

\section{LINDA MATIGNON}

UA

MAME E MARIETOU LO

UNIMES

MAURO VICENTINI

UB

DROCHS PETRI VALENCIA

Pontificia Universidad Javeriana

MARCOS V. PALMEIRA-MELLO

UFF: Universidade Federal Fluminense

MURIEL SYLVESTRE

UA

NADY PASSE-COUTRIN

UA

ANUBIS VEGA-RUA

Pasteur Institut of Guadeloupe: Institut Pasteur de Guadeloupe

Antonio Domenech

UV

\section{ZOHRA BENFODDA}

UNIMES: Universidade Metropolitana de Santos

\section{Patrick Meffre}

Centre Universitaire de Formation et de Recherche-Unimes: Universite de Nimes

Gerardo Cebrián-Torrejón ( $\sim$ gerardo.cebrian-torrejon@univ-antilles.fr )

Université des Antilles: Universite des Antilles https://orcid.org/0000-0002-5776-922X

\section{Research Article}

Keywords: Pseudosphinx tetrio, Apocynaceae, Allamanda cathartica, Chemical ecology, Phytochemistry, Electrochemical ecology, PCA analysis.

Posted Date: August 10th, 2021 
DOl: https://doi.org/10.21203/rs.3.rs-776886/v1

License: (c) (1) This work is licensed under a Creative Commons Attribution 4.0 International License. Read Full License 


\title{
CHEMOECOLOGICAL STUDY OF TROPHIC INTERACTION BETWEEN Pseudosphinx tetrio L. LARVAE AND Allamanda cathartica $\mathrm{L}$.
}

\author{
LINDA MATIGNON ${ }^{1}$, MAME MARIETOU LO ${ }^{2}$, MAURO VICENTINI ${ }^{3}$, DROCHS PETRI VALENCIA ${ }^{4}$, \\ MARCOS V. PALMEIRA-MELLO ${ }^{5}$, MURIEL SYLVESTRE ${ }^{1}$, NADY PASSE-COUTRIN ${ }^{1}$, ANUBIS VEGA- \\ RUA $^{6}$, ANTONIO DOMENECH ${ }^{7}$, ZOHRA BENFODDA $^{2}$, PATRICK MEFFRE ${ }^{2}$ and GERARDO CEBRIÁN- \\ TORREJÓN ${ }^{1, *}$
}

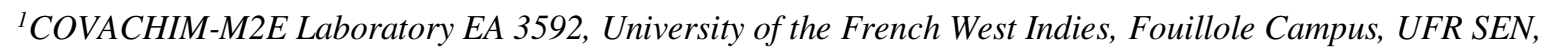
Department of Chemistry, Pointe-à-Pitre Cedex, France.

${ }^{2}$ CHROME laboratory, EA7352, University of Nîmes, F- 30021 Nîmes Cedex 1, France

${ }^{3}$ Instituto de Química, Unversidade de Brasília, Campus Universitário Darcy Ribeiro, Brasília, DF, 70297-400, Brazil.

${ }^{4}$ Pontificia Universidad Javeriana sede Cali, Departamento de Ciencias Naturales y Matemáticas, Calle 18 No. 118-250 Cali, Colombia.

${ }^{5}$ Instituto de Química, Universidade Federal Fluminense, Outeiro S. João Batista S/N, 24020-141 Niterói, RJ, Brazil.

${ }^{6}$ Laboratory of vector control research, Institute Pasteur of Guadeloupe - Lieu-dit Morne Jolivière, 97139 Les Abymes, Guadeloupe, France

${ }^{7}$ Departament de Química Analítica, Facultat de Química, Universitat de València, Dr. Moliner 50, 46100 Burjassot, Valencia, Spain.

${ }^{*}$ Corresponding author.COVACHIM-M2E Laboratory EA 3592, University of the French West Indies, Fouillole Campus, UFR SEN, Department of Chemistry, Pointe-à-Pitre Cedex, France. E-mail address: gerardo.cebriantorrejon@univ-antilles.fr (G. Cebrian-Torrejon).

Abstract- The larval caterpillar Pseudosphinx tetrio L. is a species that feeds specifically on plants belonging to the family Apocynaceae. The genus Allamanda includes many shrubs or flowering trees which are grown throughout the tropical regions and are well known due their several biological properties. This work explores the interaction between the caterpillar and this plant using several analytical techniques such as thin layer chromatography, nuclear magnetic resonance spectroscopy, high performance liquid chromatography coupled with mass spectrometry and cyclic voltammetry. Further, a multivariate data analysis was performed in attempt to obtain better insights regard the samples.

The results point out the similar profile between the health and herbivore Allamanda cathartica L.'s leaves and the caterpillars' faeces. The similar analytical profile between the leaves of $A$. cathartica and the faeces of $P$. tetrio, as well as the difference with the caterpillar's bodies suggest a selective excretion of compounds by the caterpillar. These compounds found selectively in the faeces (and not in the body) can explain that $P$. tetrio can feed this toxic Apocynaceae species. 
Key Words - Pseudosphinx tetrio, Apocynaceae, Allamanda cathartica, Chemical ecology, Phytochemistry, Electrochemical ecology, PCA analysis. 


\section{INTRODUCTION}

Commonly known as "glutton caterpillar", Pseudosphinx tetrio L. (Linnaeus 1771) is a velvety black caterpillar (Lepidopterae) about $12 \mathrm{~cm}$ long, with bright yellow stripes along the body and a bright orange-red head (Haxaire and Herbin 2000; Haxaire and Rasplus 1986). P. tetrio has the ability to eat up to twice its weight in food during a day this fact explains the common name of "glutton caterpillar". According to aposematic hypothesis, it becomes toxic for its predators upon to absorb toxic compounds present in the latex of some plants (Warrell 2009). The larva of $P$. tetrio feeds preferentially on the leaves of plants as Allamanda cathartica $\mathrm{L}$. (Apocynaceae), which are rich in toxic latex (Rajamanickam and Sudha 2013).

Allamanda cathartica L. (Petricevich and Abarca-Vargas 2019), also known as yellow Allamanda in the West Indies, is a widely grown shrub and frequently recognized as golden trumpet vine (Khanam et al. 2018). It is a native plant from Brazil (Pessoa et al. 2006) used in traditional medicine to treat jaundice (Nayak et al. 2006), presenting several biological activities as antioxidant (Hammeed et al. 2014), antimicrobial (Sharmin et al. 2015), antifungal (Souza et al. 2020), antimalarial (Conrad et al. 2013), anti-inflammatory (Boeing et al. 2018) and anticancer (Wong et al. 2011).

In the context of tropical chemical ecology, many different plant-herbivore interactions are highly specialized (Forister et al. 2015). In a self-defence process, plants can biosynthesize secondary metabolites to reduce herbivory. In turn, herbivores can react to these compounds in attempt to metabolize, excrete selectively or to use them for own defence (upon incorporation into the body) (Eisner and Meinwald 1995; Opitz and Muller 2009). Herein, we will explore the chemical interaction between P. tetrio and A. cathartica by several analytical methods, including an innovative electrochemical approach (named electrochemical ecology) and multivariate analysis in order to obtain better insights regard their specific interaction.

\section{MATERIAL AND METHODS}

Sample's preparation. Healthy and herbivored leaves of A. cathartica, as well as $P$. tetrio caterpillars have been collected in Guadeloupe Island (French West Indies), specifically in "Le Gosier" city $\left(16^{\circ} 13^{\prime} 00.5^{\prime \prime} \mathrm{N}\right.$ $61^{\circ} 31^{\prime} 09.9^{\prime \prime}$ ). Leaves were cleaned (with distilled water) and lyophilized. The caterpillars have been kept in a cage for 24 hours, to collect their faeces, and starved for 48 hours to use their corpse in the evaluation of biomolecules incorporation to the caterpillar bodies excluding the digestive material. Finally, the dried leaves, the caterpillars' bodies and faeces were lyophilized and powdered.Afterwards, $50 \mathrm{~g}$ of each sample was extracted by maceration extraction for 48 hours. The maceration was carried out in a ternary mixture of dichloromethane/methanol/distilled water (Yu Lin et al 2007; Mushtaq et al 2014) (1:1:1 v/v, $200 \mathrm{~mL}$ ). Upon the complete extraction, the solutions were filtered and extracted by liquid-liquid extraction and two phases were obtained for each manipulation (Table 1).Finally, these phases have been dried by rotary evaporation. 
Table 1 Phases obtained for each manipulation after liquid-liquid extractions

\begin{tabular}{|l|c|c|}
\hline & Organic Phase & Aqueous Phase \\
\hline Healthy $A$. cathartica leaves & 1.2 & 2.2 \\
\hline Herbivored A. cathartica leaves & 1.3 & 2.3 \\
\hline Caterpillars & 1.4 & 2.4 \\
\hline Caterpillar's faeces & 1.5 & 2.5 \\
\hline
\end{tabular}

Analysis and quantification. Analysis were performed using several techniques such as thin layer chromatography (TLC), nuclear magnetic resonance spectroscopy ( $\left.{ }^{1} \mathrm{H}-\mathrm{NMR}\right)$, high performance liquid chromatography coupled with mass spectrometry (HPLC-MS) and cyclic voltammetry (CV).

Thin layer chromatography $(T L C)$. The thin layer chromatography of all the organic phases were carried out with a gradient of two different mixtures of elution solvents composed by $\mathrm{CH}_{2} \mathrm{Cl}_{2} / \mathrm{MeOH}$ or $n$ hexane/AcOEt with a volume of $10 \mathrm{~mL}$ in different proportions (80/20, 50/50, 90/10, 95/5, 99/1, 50/50). Further TLCs of all aqueous phases were made on cellulose TLCwith a mixture of $\mathrm{H}_{2} \mathrm{O} / \mathrm{MeOH}$ elution solvent in different proportions $(50 / 50-100)$ as mobile phase.

Nuclear magnetic resonance spectroscopy $\left({ }^{1} H\right.$-NMR). $15 \mathrm{mg}$ of each extract was solubilized in $650 \mu \mathrm{L}$ of DMSO and transferred to NMR tubes. 1D ${ }^{1} \mathrm{H}$ nuclear magnetic resonance spectra were recorded with a BRUKER Avance $300 \mathrm{MHz}$ spectrometer equipped with a BBO probe and automatic tube changer. Chemical shifts $(\delta)$ are expressed in ppm relative to tetramethylsilane (TMS) taken as external reference and internal calibration is performed on the solvent signal. All spectra were processed using Topspin 2.1 software. The classical 1D proton with a $90^{\circ}$ pulse width was performed. The spectra were acquired using 256 scans and 2 dummy scans of $32 \mathrm{~K}$ data points with a spectral width of $5411.255 \mathrm{~Hz}$.

High performance liquid chromatography coupled with mass spectrometry (HPLC-MS). Triplicates of each extract were made and dissolved in $750 \mu \mathrm{L}$ of methanol (LCMS grade) and $750 \mu \mathrm{L}$ of ultra-pure water (ElgaPurelab Classic). The mixtures were sonicated in the ultrasonic bath then filtered on $13 \mathrm{~mm}$ and $0.45 \mu \mathrm{m}$ PTFE filters and placed in amber vials. The analysis is performed on a Waters (Milford, MA, USA) Alliance e2695 liquid chromatographic system, equipped with aWaters 2996 photodiode array detector (PDA), coupled with the orthogonal quadrupole mass spectrometer (Micromass ZQ, Manchester, UK). The systems were controlled by MassLynx v.4.1 software (Micromass, Manchester, UK). The mass is equipped with an electrospray ionization ESI (Waters) source, the ionization is performed in positive mode. A double detection is carried out by mass spectrometry in ESI (range 71 to $1200 \mathrm{Da}$ ) and by a PDA diode array detector (UV detection between 210-400 nm). The analytical column was XTERRA MS C18 column ( 2.1 x $100 \mathrm{~mm}, 3,5 \mu \mathrm{m})$ (Waters). The elution is performed with a mobile phase flow rate of $0.2 \mathrm{~mL} / \mathrm{min}$ consisting of a mixture of ultrapure water containing $0.1 \%$ formic acid (A) and methanol containing $0.1 \%$ formic acid (B). The program starts at $\mathrm{t}=0 \mathrm{~min}$ ratio (A: B) 95:5, at $\mathrm{t}=2 \min (95: 5)$, at $\mathrm{t}=5 \mathrm{~min}(70: 30)$, at $\mathrm{t}=15 \min (60: 40)$, at $\mathrm{t}=40 \min (50: 50)$, at $\mathrm{t}=55$ $\min (45: 55)$, at $t=60 \min (0: 100)$, at $t=65 \min (0: 100)$, at $t=75 \min (95: 5)$ and at $t=80 \min (95: 5)$. The injection volume was $10 \mu \mathrm{l}$ and detection was at $280 \mathrm{~nm}$ and at $320 \mathrm{~nm}$. The ESI-MS parameters were as follows: desolvation gas $\left(\mathrm{N}_{2}\right)$ flow rate: $650 \mathrm{~L} / \mathrm{h}$; cone gas flow rate: $40 \mathrm{~L} / \mathrm{h}$; drying gas temperature: $450{ }^{\circ} \mathrm{C}$; source temperature: $120^{\circ} \mathrm{C}$; capillary voltage: $3 \mathrm{kV}$; cone voltage: $85 \mathrm{~V}$; RF lens voltage: $0.1 \mathrm{~V}$. 
Cyclic Voltammetry (CV). Cyclic voltammograms were obtained at $298 \pm 1 \mathrm{~K}$ in a conventional threeelectrode cell using a platinum wire auxiliary electrode and an $\mathrm{Ag} / \mathrm{AgCl}(3 \mathrm{M} \mathrm{NaCl})$ reference electrode. Measurements were carried out with $\mathrm{CH}$ I660 equipment using $0.10 \mathrm{M}$ potassium phosphate buffer at $\mathrm{pH} 7.0$ as a supporting electrolyte. The working electrode was prepared by evaporating $50 \mu \mathrm{L}$ of an ethanol (EtOH) suspension of extract of interest, ground leaves orinsect samples under air on a glassy carbon electrode (GCE, BAS MF 2012, geometrical area $0.071 \mathrm{~cm}^{2}$ ). In order to mimic the natural environment, no degasification of the electrolyte was performed.

Principal Component Analysis (PCA). The raw data from HPLC-MS was exported as netCDF files, using DataBridge software (Waters, USA), and pre-processed using XCMS Online (Mahieu et al 2016; Tautenhahn et al 2012) for feature detection, retention time correction and alignment of metabolites detected on HPLC-MS analysis. The dataset was created with 12 samples from each organic and aqueous extract fraction (3 samples from each manipulation (see Table 1)). Peak detection was performed using cent Wave peak detection $(\Delta \mathrm{m} / \mathrm{z}=10 \mathrm{ppm}$; minimum peak width, $5 \mathrm{~s}$; maximum peak width, $20 \mathrm{~s})$ and mzwid $=0.015$, $\operatorname{minfrac}=0.5$, bw $=5$ were used for retention time alignment. The processed data (csv file) was further exported to MetaboAnalyst 4.0 (Chong et al 2018). All data variables were scaled by pareto method prior to PCA. ).PCA is an unsupervised method commonly used to identify patterns between multivariate samples (Wold et al 1987; Jolliffe, 2005) and was recently employed on chemical variability of Allamanda cathartica extracts (Rodrigues et al 2020).

\section{RESULTS AND DISCUSSION}

TLC analysis. First, a TLC study has been conducted. The different results of this approach were exposed in the Table2. In our first hypothesis (Hyp. 1), we propose that the caterpillars ingest and store certain metabolites (for example the metabolite with a $\mathrm{R}_{\mathrm{f}}$ of 0.16 on TLC 3 (orange color)). The second hypothesis proposed (Hyp. 2), also illustrated in Table 2, refers to a selective excretion of an unidentified molecule by the caterpillars (for example the metabolite with a $R_{\mathrm{f}}$ of 0.95 on TLCs 2 and 3 (blue color)). Finally, the third hypothesis (Hyp. 3), is related with the response of the healthy plant to the herbivory (for example the metabolite with a $\mathrm{R}_{\mathrm{f}}$ of 0.28 on TLC 1 (pink color), as this metabolite is present in the healthy leaves and not in the herbivored ones. The opposite case can be observed with the metabolite with a Rf of 0.18 on TLC 4 (green color) that is only seen in healthy leaves and thus could be considered as a metabolic marker for herbivory. 
Table 2 Organic phases obtained with TLCs results. (A) healthy A. cathartica leaves, (B) herbivored $A$. cathartica leaves, (C) caterpillar's bodies and (D) caterpillars's faces. Solvent percentages are presented as highest polarity in solution $(\mathrm{MeOH}$ and EtOAc)*

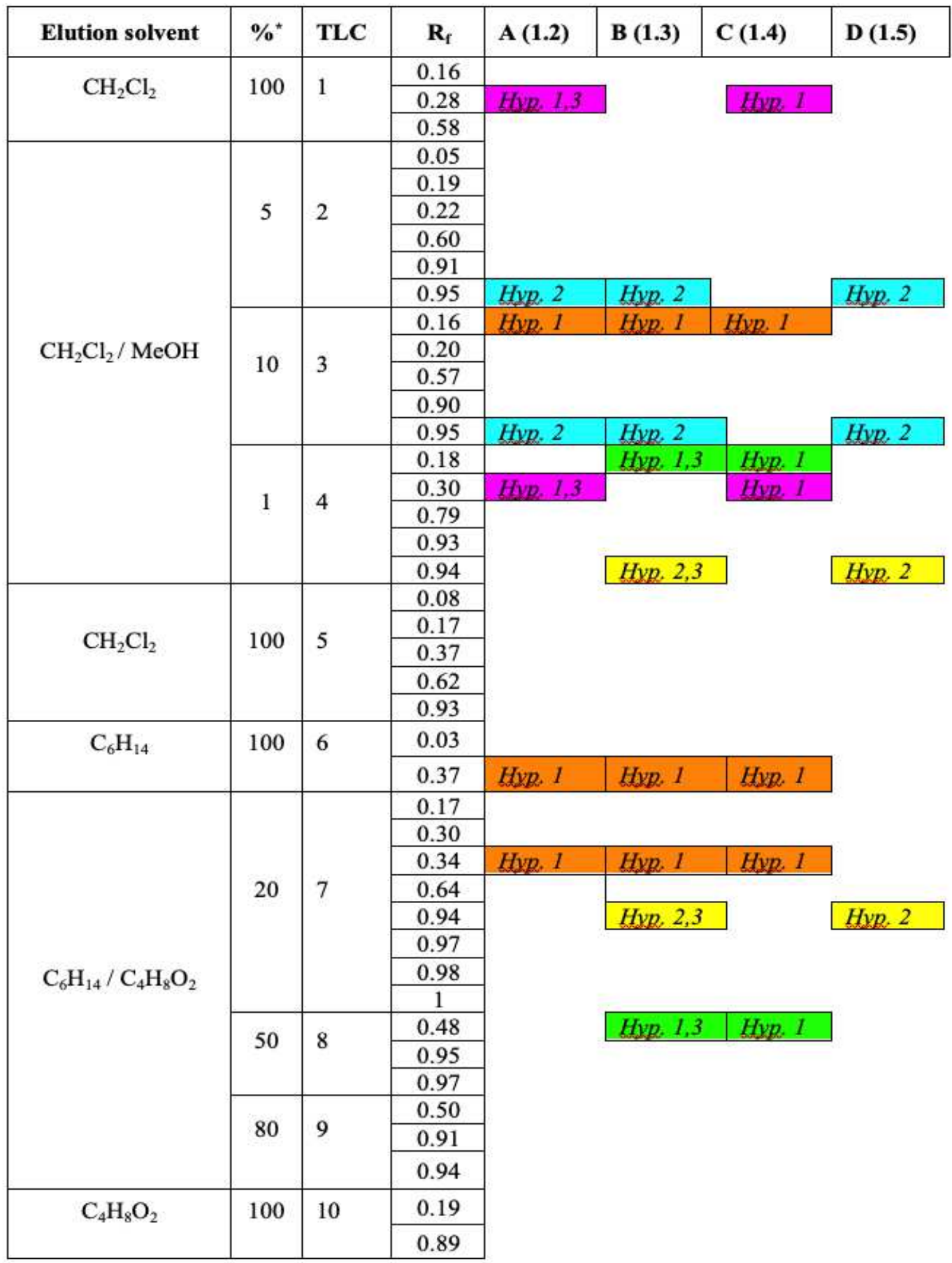

* Similarly, metabolite between two extracts or more are described in colors: orange: A, B and C; blue: A, B and D; pink: A and C; yellow: B and D. Hypothesis that can be illustrated by each compound are cited.

${ }^{1} H$ NMR. The ${ }^{1} \mathrm{H}$ NMR data were obtained only from plants and caterpillar organic extracts, using DMSO- $\mathrm{d}^{6}$ as solvent. Solvents signals from deuterated DMSO and residual water at 2.5 and $3.3 \mathrm{ppm}$, respectively, were removed (Fig. 1). The analysis indicates minor differences between spectra of health and herbivored Allamanda leaves. This result is contradictory with regards our Hypothesis. 3 (were a reaction of the plant to aggression was attended). 
The spectra derived from caterpillars' bodies and faeces present big differences between the samples, and the chemical profile of healthy Allamanda and caterpillar's faeces are very similar. This result confirms our Hypothesis 2, showing the similarity between the chemical profile of A. cathartica leaves and caterpillars' faeces when compared to the caterpillars' bodies. These similarities and dissimilarities confirm our hypothesis (Hyp. 3) of the selective excretion of toxic compounds.

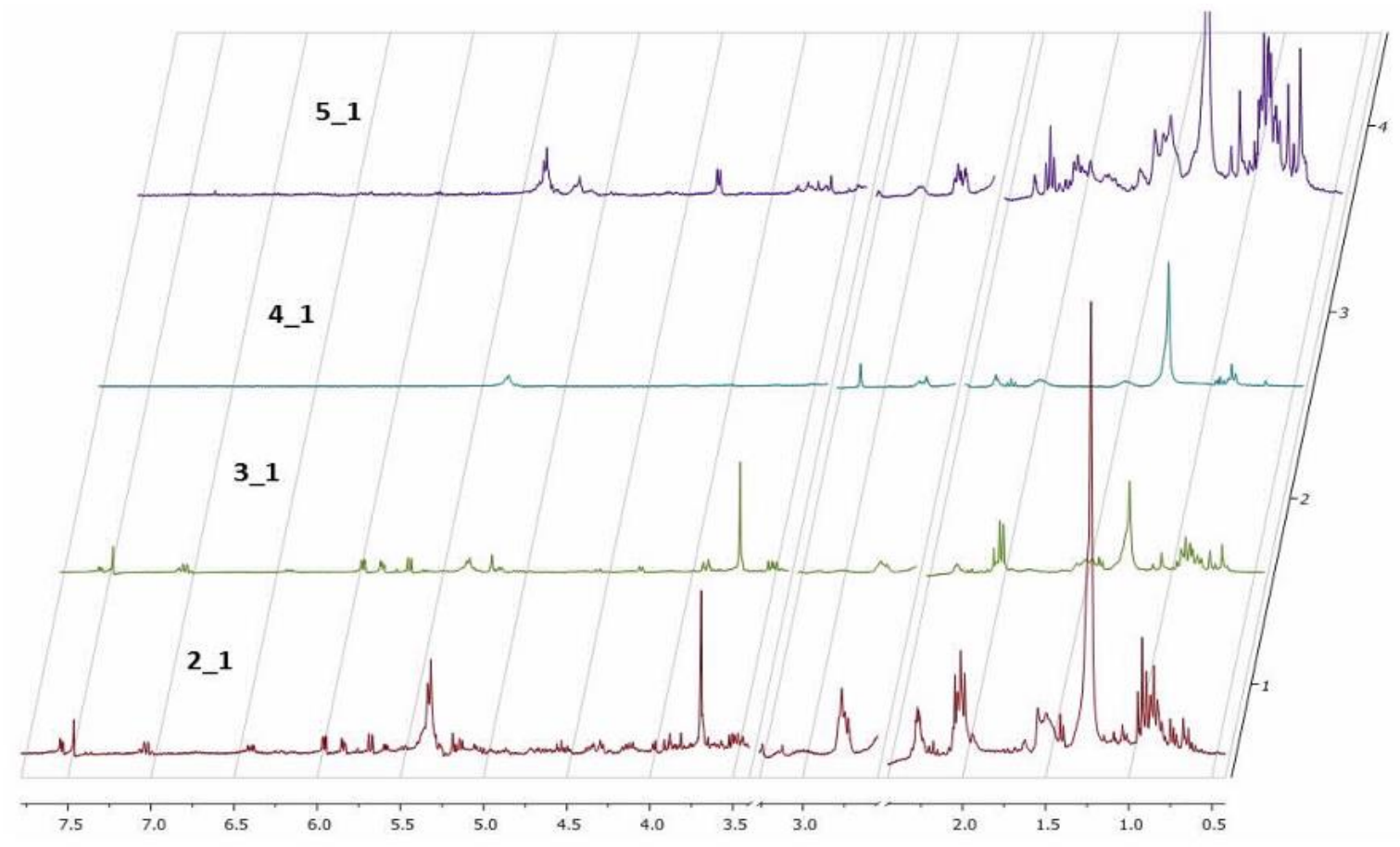

Fig. $1{ }^{1} \mathrm{H}$ NMR of organic extracts in DMSO-d ${ }^{6}$. (2_1) Healthy Allamanda leaves; (3_1) Herbivored Allamanda leaves; (4_1) Caterpillar's bodies and (5_1) Caterpillar's faeces.

HPLC-MS. In this study, the samples containing the healthy and herbivored leaves of Allamanda cathartica, as well the caterpillars and their faeces were investigated using chromatographic techniques (Barny et al 2021; Marques et al 2018; Prabhadevi et al 2012; Khanam et al 2018) (Fig.2). The similar profile observed on these spectra, suggests the presence of the same main compounds in the healthy (A) and herbivored (B) A. cathartica leaves, with similar retention times (RT) of $20.00 \mathrm{~min}$ and $20.50 \mathrm{~min}$, respectively. A second compound can be identified in these spectra with comparable retention times (RTs: 25.52 min and $26.02 \mathrm{~min}$ ). These results are opposed to our hypothesis 3 (as we can see in the TLCs and ${ }^{1} \mathrm{H}$ NMR profiles). The analysis indicates a presence of this compound in the caterpillar's faeces (D, RT: $25.73 \mathrm{~min}$ ) but not in their body (C), confirming as well our hypothesis 2 (in agreement with the ${ }^{1} \mathrm{H}$ NMR and TLC results). Finally, the results show that the compounds found in P. tetrio's bodies (C, RT: $20.43 \mathrm{~min}$ and $25.66 \mathrm{~min}$ ) are significantly different than other compounds found in the faeces (confirming as well our hypothesis 2 ). 


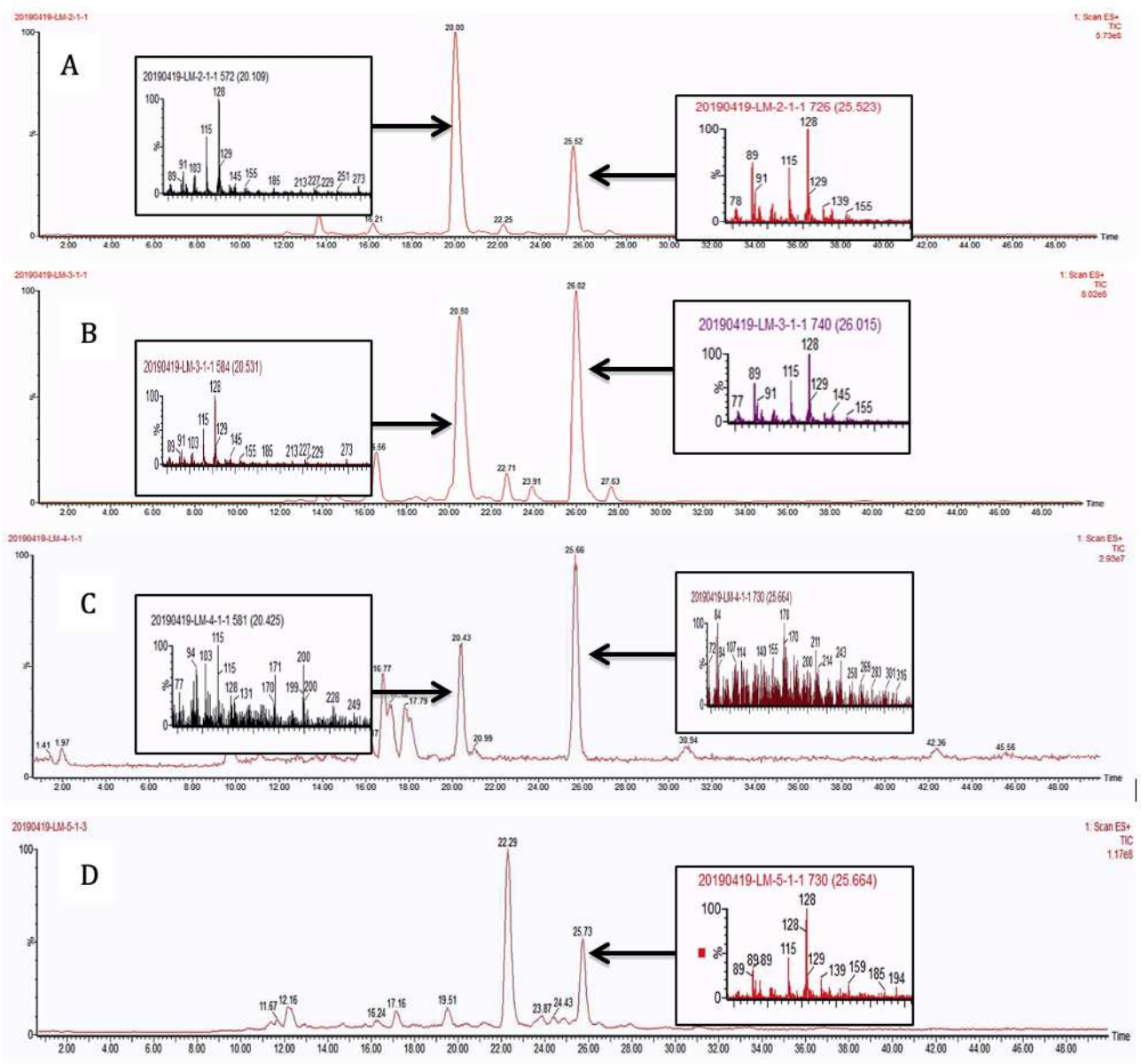

Fig. 2 HPLC-MS profiles of (A) healthy and (B) herbivored leaves of A. cathartica and (C) caterpillar' body and (D) caterpillar's faeces

Electrochemical investigation. Cyclic voltammetry studies have been employed in attempt to investigate possible interactions between different compounds and were previously used for monitoring plant defence against external stressors (Cebrian-Torrejon et al 2015; Palmeira-Mello et al 2021; Doménech-Carbó et al 2015; Rozoy et al 2013).Here, the predation of A. cathartica by Pseudosphinx tetrio has been electrochemically monitored via cyclic voltammetry $(\mathrm{CV})$. We investigate the voltammetric response of films (at the surface of a glassy carbon electrode) of organic and aqueous extracts of healthy and predated leaves of the plant and samples of body and excrements of $P$. tetrio in $0.10 \mathrm{~mol} \mathrm{~L}^{-1}$ phosphate solution buffer at $\mathrm{pH}$ 7.0. The reported methodology is ultimately based on the voltammetry of microparticles (VMP) technique (Domenech-Carbó et al 2013).

The behaviour of films on glassy carbon electrodes of healthy and predated leaves of $A$. cathartica are showed in Fig.3. It was observed a set of three chemically irreversible oxidation processes $\mathrm{A}_{1}, \mathrm{~A}_{2}$ and $\mathrm{A}_{3}(0.28 \mathrm{~V}$, $0.65 \mathrm{~V}$ and an undefined shoulder near to $1.00 \mathrm{~V}$ respectively). Where as $\mathrm{A}_{1}$ and $\mathrm{A}_{2}$ peaks decrease upon cycling until a totally passivated and stable state is attained approximately at the second cycle, an increasing of $A_{3}$ peak was observed. Thus, the variations in the ratio of peaks $\mathrm{A}_{1}$ and $\mathrm{A}_{3}$, can infer differences in the nature of the redox species in A. cathartica healthy and herbivored leaves. These oxidation processes represent a profile observed in several vegetable species and are attributed to the oxidation of polyphenolic organic compounds. In fact, the voltammogram of the predated leaves exhibits the same signals than healthy leaves, but the peak $A_{1}$, is depleted while the signal $A_{3}$ is enhanced. Finally, a reduction process approximately at $-1,0 \mathrm{~V}$ can be observed when the potential sweep is reversed 
towards less positive potentials. Although these processes are slightly more negative for the healthy than for herbivore leaves, both correspond to the typical behaviour of the oxygen reduction in water. This result is basically opposed to our hypothesis 3 about the chemical response to the herbivory, but by this technique we can identify slight differences between healthy and herbivore leaves maybe related with polyphenols (reaction against oxidative stress) (Singh et al 2021).
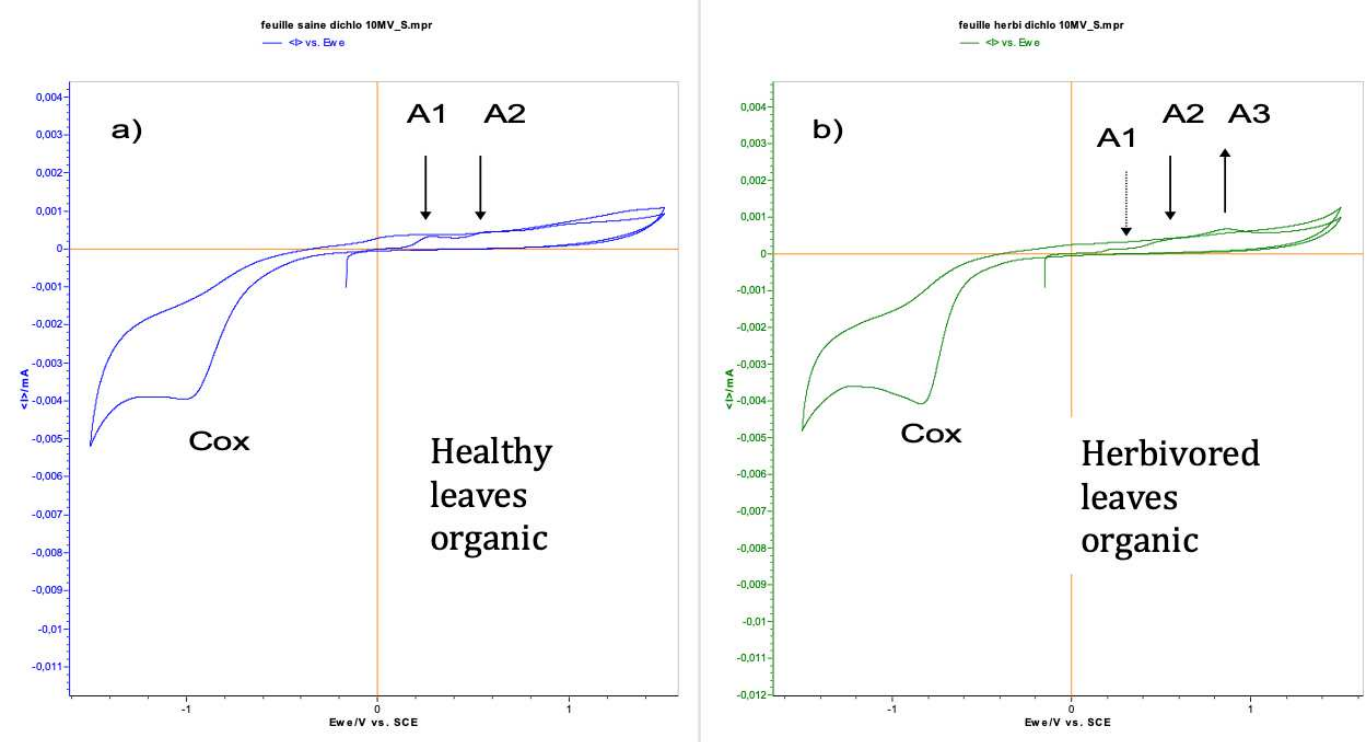

Fig. 3 Cyclic voltammograms of films from a) healthy and b) herbivored or predated leaves of A. cathartica on glassy carbon electrode in contact with air-saturated $0.10 \mathrm{M}$ phosphate buffer at $\mathrm{pH}$ 7.0. scan rate $10 \mathrm{mV} \mathrm{s}^{-1}$

The cyclic voltammetry of films on glassy carbon electrodes of $P$. tetrio's bodies and its excrements after predation on leaves of $P$. tetrio are presented on Fig.4. The cyclic voltammogram does not show clear oxidation process in the initial anodic scan for the body of $P$. tetrio, but revealed three oxidation processes at $0.22,0.45$ and $0.78 \mathrm{~V}$, for its faeces, namely $\mathrm{A}_{1}, \mathrm{~A}_{2}$ and $\mathrm{A}_{3}$, respectively, which are similar to those found for $A$. cathartica analysis. Once again, a typical oxygen reduction process in water was observed incathodic region for both analysis. Further, a characteristic signal $\mathrm{C} 1$ appears in both samples suggesting the presence of oxidized metabolite of $P$. tetrio. This result confirms the hypothesis 2 in agreement with the other analytical approaches. 

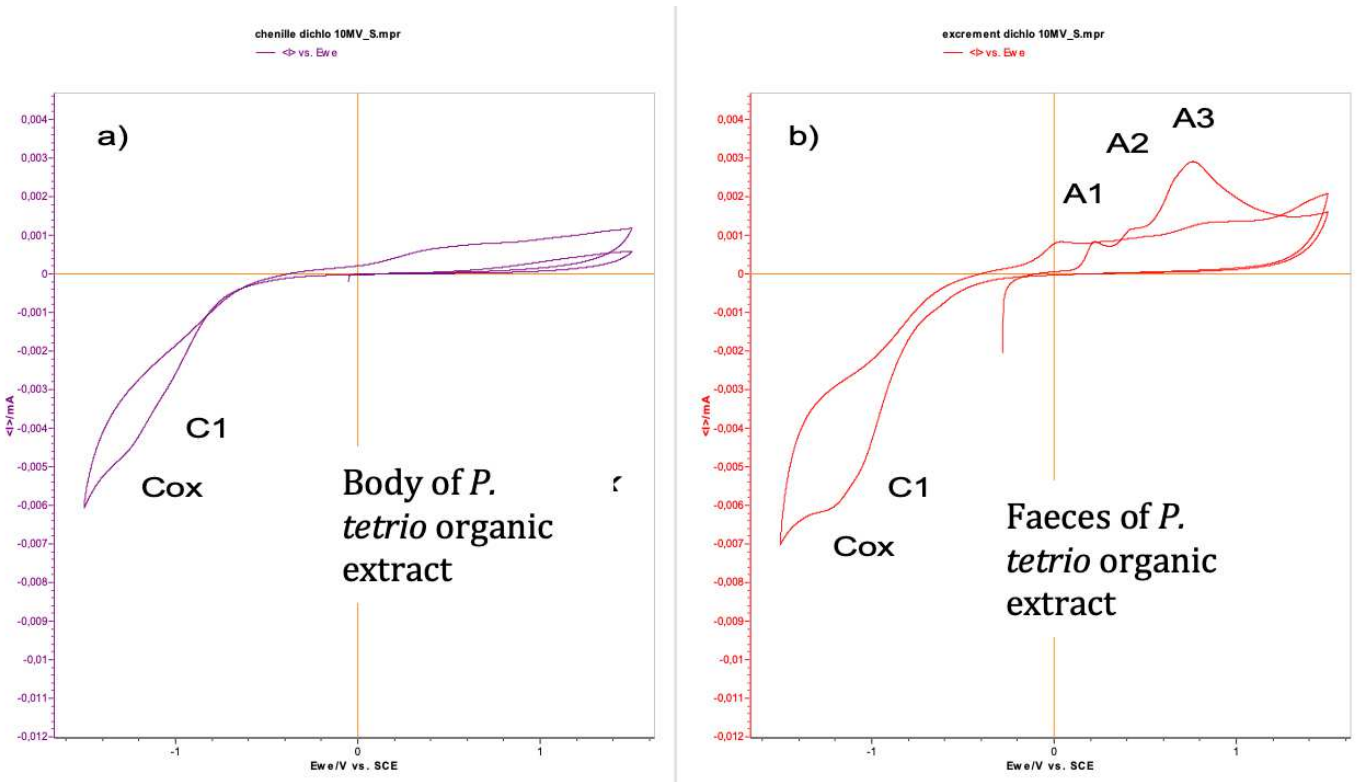

Fig. 4 Cyclic voltammograms of films from a) Pseudosphinx tetrio's bodies and b) Pseudosphinx tetrio's excrements after predation on leaves of $A$. cathartica on glassy carbon electrode in contact with air-saturated $0.10 \mathrm{M}$ phosphate buffer at $\mathrm{pH}$ 7.0. Potential scan rate $10 \mathrm{mVs}^{-1}$.

A comparison between the voltammograms of films from the water extracts of healthy and predated leaves of A. cathartica in contact with air-saturated $0.10 \mathrm{M}$ phosphate buffer at $\mathrm{pH} 7.0$ was performed (Fig. 5). Here, the signal A1 appears clearly recorded in the healthy leaves and is accompanied by a well-defined cathodic peak at $1.25 \mathrm{~V}\left(\mathrm{C}_{2}\right)$. This signal $\mathrm{C}_{2}$ disappears in the voltammograms of the predated leaves while the signal $\mathrm{A}_{1}$ decreases and the signal $\mathrm{A}_{3}$ at $0.78 \mathrm{~V}$ becomes clearly marked. This result confirms the hypothesis 3 , showing a reaction of the leaves against the herbivory, the disparition of signal $\mathrm{C}_{2}$ and the apparition of signal $\mathrm{A} 3$ as result of the herbivory.

This voltammetry is to some extent reproduced in the aqueous extracts of $P$. tetrio and its excrements, reproduced in Fig. 6, thus suggesting the existence of common electroactive compounds. 

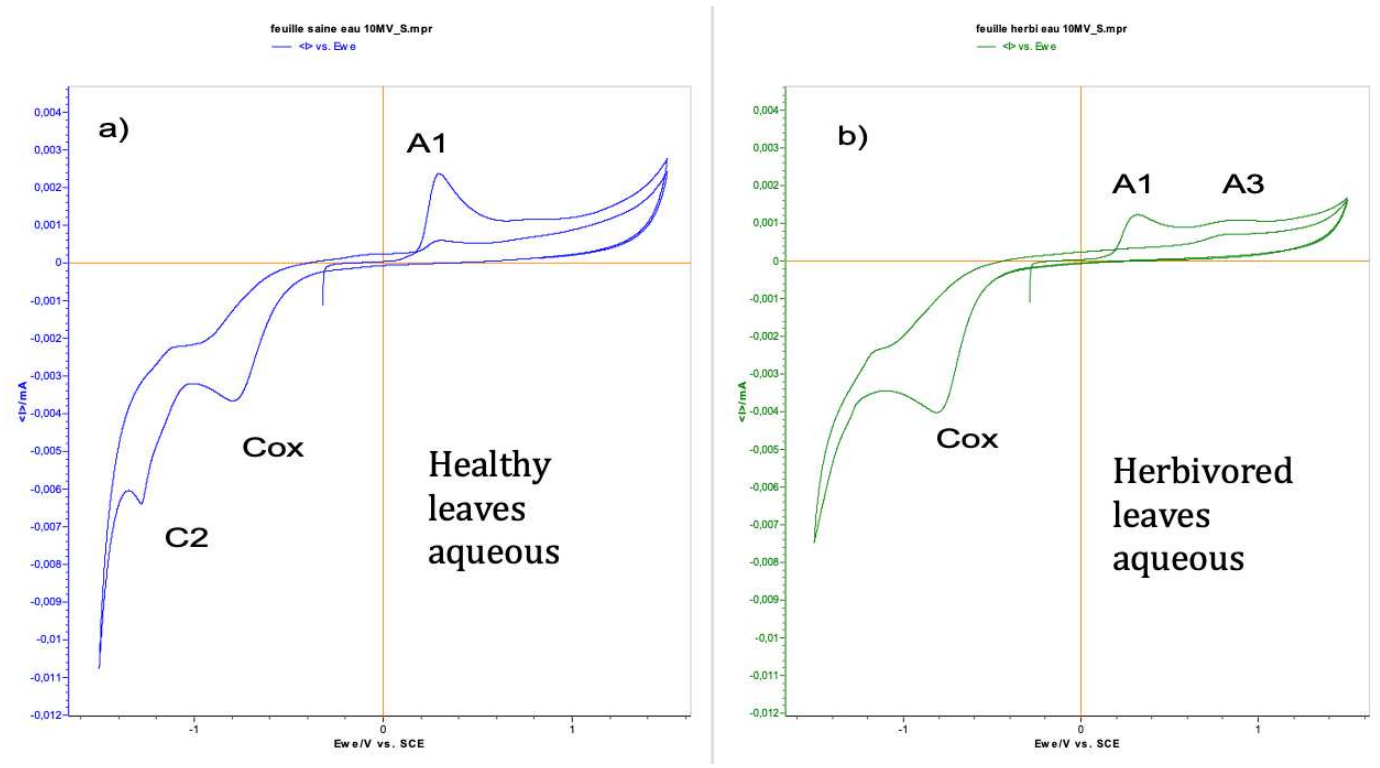

Fig. 5 Cyclic voltammograms of films from the water extracts of a) healthy and b) predated leaves of $A$. cathartica on glassy carbon electrode in contact with air-saturated $0.10 \mathrm{M}$ phosphate buffer at $\mathrm{pH}$ 7.0. Potential scan rate $10 \mathrm{mV}$ $\mathrm{s}^{-1}$
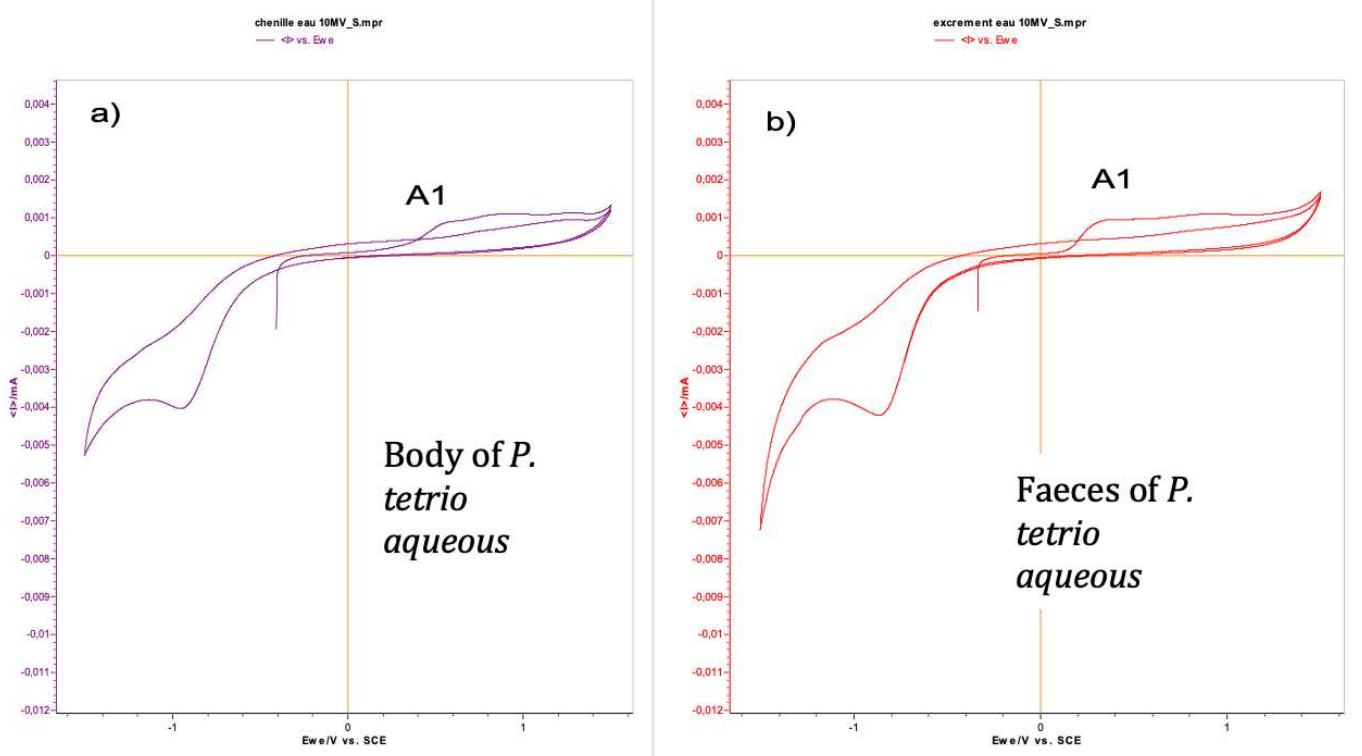

Fig. 6 Cyclic voltammograms of films from water extracts of a) P. tetrio's bodies and b) its excrements after predation on leaves of $A$. cathartica on glassy carbon electrode in contact with air-saturated $0.10 \mathrm{M}$ phosphate buffer at $\mathrm{pH}$ 7.0. Potential scan rate $10 \mathrm{mV} \mathrm{s}^{-1}$.

PCA Analysis. A total of 24 chromatograms were acquired using HPLC-EI-MS, 12 from aqueous fraction and 12 from organic fraction (3 biological replicates for each species). To identify differences in the metabolites or even in their concentration in the samples, the set of 24 samples was analyzed obtained from XCMS and used for data analysis. Two spreadsheets were obtained after data processing of HPLC-MS analysis, with 168 and 412 variables from organic and aqueous fractions, respectively (retention time $\mathrm{m} / \mathrm{z}$ ). In the PCA analysis, two plots were generated, namely score and loading plots. The first one shows the samples grouping, whereas the second one indicates the contribution of each variable to these samples. The PCA analysis were focused on the detection of any inherent pattern within the data. As observed in Fig.7, samples of healthy and 
herbivored Allamanda leaves are close related, with small difference each other, when compared with the caterpillars' bodies and faeces. Further, when all samples are compared, the predated and not predated leaves from Allamanda are very similar to each other, and different from the other samples. In addition, the Caterpillars' bodies extracts present a great difference. In Fig. 8 (loadings plot) are presented the variables that influences the grouping observed.
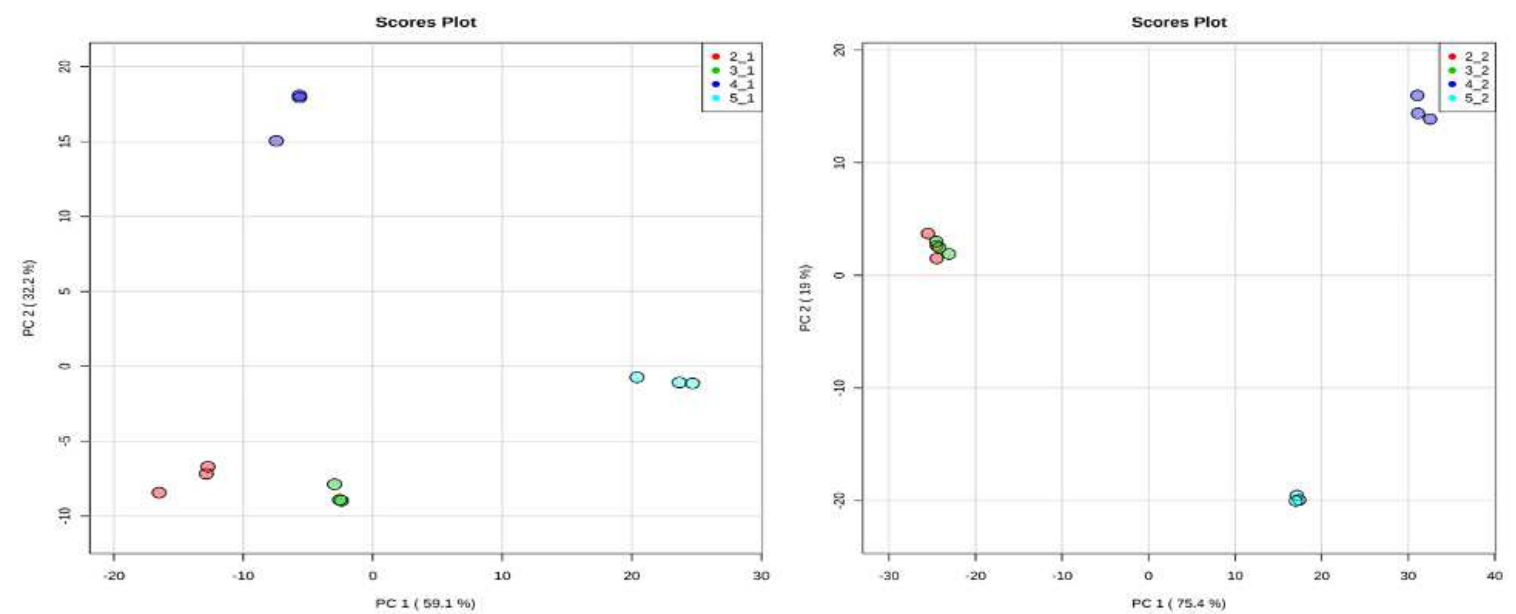

Fig. 7 Score plot of 12 samples of organic and aqueous extracts of all manipulation, obtained from 168 (left) and 412 (right) variables, respectively. (2_1and 2_2) red circle, healthy Allamanda leaves; (3_1and 3_2) green circle, herbivored Allamanda leaves; (4_1and 4_2) blue circle, caterpillar's bodies and (5_1and 5_2) light blue circle, caterpillar's faeces.
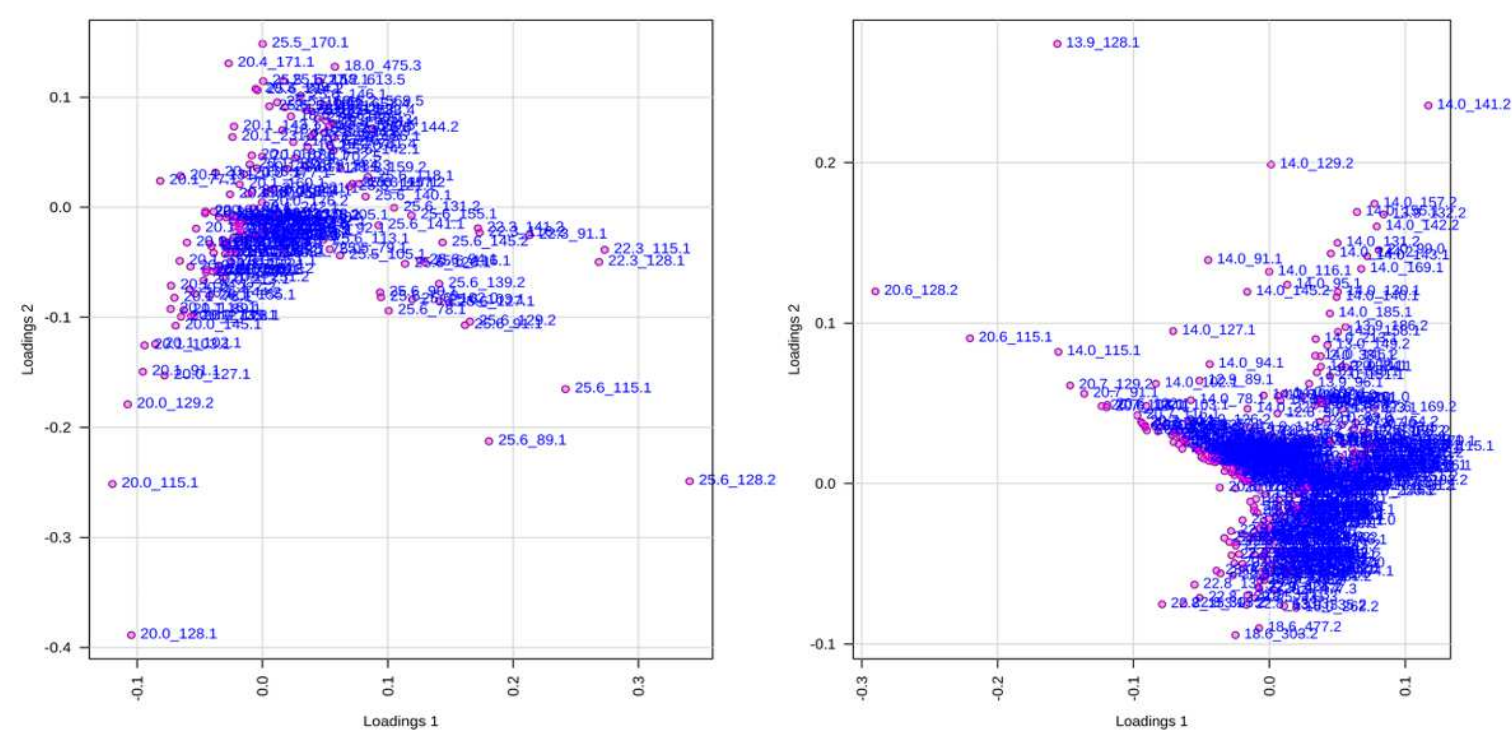

Fig. 8 Score plots of 12 samples of organic and aqueous extracts of all manipulation, obtained from 168 (left) and 412 (right) variables, respectively. Each dot represents one variable (retention time m/z).

In conclusion, we investigated the plant-herbivore interaction between caterpillar Pseudosphinx tetrio and the flowering plant Allamanda cathartica. In this approach, several techniques were employed in attempt to gain better insights regarding this trophic relationship, such as TLC, ${ }^{1} \mathrm{H}$ NMR, HPLC-MS (analyzed by a 
multivariate PCA) and an innovative approach by electrochemical methods (electrochemical ecology). The results point out the similar profile between the health and herbivored A. cathartica's leaves and the caterpillars' faeces. The similar analytical profile between the leaves of A. cathartica and the faeces of $P$. tetrio, as well as the difference with the caterpillar's bodies suggest a selective excretion of compounds by the caterpillar (proposed hypothesis 2). These compounds found selectively in the faeces (and not in the body) can explain that P. tetrio can feed this toxic Apocynaceae species.

\section{DECLARATIONS.}

Funding. The authors would like to acknowledge for financial support to the projet "AgroEcoDiv" from European Union Fund (FEDER) and "Région Guadeloupe". We would also like the Caribaea Initiative association for two month study grant from Matignon.

Conflicts of interest/Competing interests (include appropriate disclosures). The authors declare that they have no conflict of interest.

Availability of data and material. Not applicable.

Additional declarations for articles in life science journals that report the results of studies involving humans and/or animals ethics approval. Not applicable

Consent to participate (include appropriate statements). Not applicable.

Consent for publication (include appropriate statements). Not applicable

\section{REFERENCES}

Haxaire J, Herbin D (2000) Les Lépidoptères Sphingidae de Bolivie. Ecologie et systématique. 2ème Partie : les sous-familles des Smerinthinae et Macroglossinae pro parte (1).

Haxaire J, Rasplus J-Y (1986) Contribution à la connaissance des Sphingidae de Guyane Française. le Partie. 91.

Warrell DA (2009) Researching nature's venoms and poisons. Transactions of the Royal Society of Tropical Medicine and Hygiene 103: 860-866. https://doi.org/10.1016/j.trstmh.2009.02.020.

Rajamanickam K, Sudha SS (2013) In-vitro antimicrobial activity and In-vivo toxicity of Moringa oleifera and Allamanda cathartica against multiple drug resistant clinical pathogens. Int J Pharm Bio Sci 4: B768-B775.

Petricevich VL, Abarca-Vargas R (2019) Allamanda cathartica: A Review of the Phytochemistry, $\begin{array}{llllll}\text { Pharmacology, Toxicology, and } & \text { Biotechnology. } & \text { Molecules }\end{array}$ https://doi.org/10.3390/molecules24071238. 
Khanam MN, Anis M, Ahmad, S (2018) Establishment of adventitious root cultures of Allamanda cathartica L. for the production of iridoid glycosides and its identification using HPTLC MS. Industrial Crops and Products125: 198-206. https://doi.org/10.1016/j.indcrop.2018.08.044.

Pessoa C, Costa-Lotufo LV, Levya A et al (2006) Anticancer potential of Northeast Brazilian plants. Adv Phytomed, 2: 197-211. https://doi.org/10.1016/S1572-557X(05)02012-X.

Nayak S, Nalabothu P, Sandiford S et al (2006) Evaluation of wound healing activity of Allamanda cathartica. L. and Laurus nobilis. L. extracts on rats. BMC Complement Altern Med 6: 12. https://doi.org/10.1186/14726882-6-12.

Hammeed A, Nawaz G, Gulzar T (2014) Chemical composition, antioxidant activities and protein profiling of different parts of Allamanda cathartica. Nat Prod Res 28, 2066-2071. https://doi.org/10.1080/14786419.2014.923997.

Sharmin M, Das Banya P, Paul L et al (2015) Study of microbial proliferation and the in vitro antibacterial traits of commonly available flowers in Dhaka Metropolis. Asian Pac J Trop Dis 5: 91-97. https://doi.org/10.1016/S2222-1808(14)60634-4.

Souza ES, Barcellos VA, Sbaraini N et al (2020) A Plumieridine-Rich Fraction From Allamanda polyantha Inhibits Chitinolytic Activity and Exhibits Antifungal Properties Against Cryptococcus neoformans. Front Microbiol 11:2058. https://doi.org/10.3389/fmicb.2020.02058.

Conrad OA, Dike IP, Agbara, U (2013) In vivo antioxidant assessment of two antimalarial plants-Allamanda cathartica and Bixa Orellana. Asian Pac J Trop Biomed 3: 388-394. https://doi.org/10.1016/S2221$\underline{1691(13) 60082-9 .}$.

Boeing T, Souza P, Bonomini TJ et al (2018) Antioxidant and anti-inflammatory effect of plumieride in dextran sulfate sodium-induced colitis in mice. Biomedicine \& Pharmacotherapy 99: 697-703. https://doi.org/10.1016/j.biopha.2018.01.142.

Wong SK, Lim YY, Abdullah NR et al (2011) Antiproliferative and phytochemical analyses of leaf extracts of ten Apocynaceae species. Pharmacognosy Res. 3: 100.

Forister ML, Novotny V, Panorska AK et al (2015) The global distribution of diet breadth in insect herbivores. Proc Natl Acad Sci USA 112: 442. https://doi.org/10.1073/pnas.1423042112.

Eisner T, Meinwald J (1995) National Academy of Sciences. Chemical Ecology: The chemistry of biotic interaction, Washington, DC: National Academy of Sciences Press. 
Opitz SEW, Muller C (2009) Plant chemistry and insect sequestration. Chemoecology 19 : 117. https://doi.org/10.1007/s00049-009-0018-6.

Yu Lin C, Wu H, Tjeerdema R et al (2007) Evaluation of Metabolite Extraction Strategies From Tissue Samples Using NMR Metabolomics. 3: 55-67. https://doi.org/10.1007/s11306-006-0043-1.

Mushtaq Y, Hae Choi Y, Verpoorte R et al (2014) Extraction for Metabolomics: Access to The Metabolome. Phytochem Anal 25:291-306. https://doi.org/10.1002/pca.2505.

Mahieu NG, Genenbacher JL, Patti GJ (2016) A roadmap for the XCMS family of software solutions in metabolomics. Curr Opin Chem Biol 30: 87-93. https://doi.org/10.1016/j.cbpa.2015.11.009.

Tautenhahn R, Patti GJ, Rinehart D et al (2012) XCMS online: A web-based platform to process untargeted metabolomic data. Anal Chem 84: 5035-5039. https://doi.org/10.1021/ac300698c.

Chong J, Soufman O, Li C et al (2018) MetaboAnalyst 4.0: towards more transparent and integrative metabolomics analysis. Nucleic Acids Res 46: W486-W494. https://doi.org/10.1093/nar/gky310.

Barny LA, Tasca JA, Sanchez HA et al (2021) Chemotaxonomic investigation of Apocynaceae for retronecinetype pyrrolizidine alkaloids using HPLC-MS/MS. Phytochem 185: 112662. https://doi.org/10.1016/j.phytochem.2021.112662.

Marques JI, Alves JSF, Torres-Rêgo M et al (2018) Phytochemical Analysis by HPLC-HRESI-MS and AntiInflammatory Activity of Tabernaemontana catharinensis. Int J Mol Sci $19: 636$. https://doi.org/10.3390/ijms19020636.

Prabhadevi V, Sahaya SS, Johnson M et al (2012) Phytochemical studies on Allamanda cathartica L. using GCMS. Asian Pac J Trop Biomed 2: S550-S554. https://doi.org/10.1016/S2221-1691(12)60272-X.

Khanam MN, Anis M, Ahmad S (2018) Establishment of adventitious root cultures of Allamanda cathartica L. for the production of iridoid glycosides and its identification using HPTLC MS. Ind Crop Prod 125: 198-206. https://doi.org/10.1016/j.indcrop.2018.08.044.

Cebrian-Torrejon G, Kablan L, Ferreira ME et al (2015) Harvesting canthinones: identification of the optimal seasonal point of harvest of Zanthoxylum chiloperone leaves as a source of 5-methoxycanthin-6-one. Nat Prod Res 29: 2054-2058. https://doi.org/10.1080/14786419.2015.1022774. 
Palmeira-Mello MV, Souza JL, Pérez AF et al (2021) Insights of Tris(2-pyridylmethyl)amine as anti-tumor agent for osteosarcoma: experimental and in silico studies. J Mol Struc 1228: 129773. https://doi.org/10.1016/j.molstruc.2020.129773.

Doménech-Carbó A, Cebrián-Torrejón G, Lopes-Souto A et al (2015) Electrochemical ecology: VIMP monitoring of plant defense against external stressors. RSC Adv 5: 61006-61011. https://doi.org/10.1039/C5RA11336A.

Rozoy E, Araya-Farias M, Simard S et al (2013) Redox properties of catechins and enriched green tea extracts effectively preserve 1-5-methyltetrahydrofolate: Assessment using cyclic voltammetry analysis. Food Chem 138 : 1982-1991. https://doi.org/10.1016/j.foodchem.2012.09.135.

Domenech-Carbó A, Labuda J, Scholz F (2013) Electroanalytical chemistry for the analysis of solids: Characterization and classification (IUPAC Technical Report).Pure Appl Chem85:609-631. https://doi.org/10.1515/ci.2013.35.3.22c.

Singh S, Kaur I, Kariyat R (2021) The Multifunctional Roles of Polyphenols in Plant-Herbivore Interactions. Int J Mol Sci 22: 1442. https://doi.org/10.3390/ijms22031442.

Wold S, Esbensen K, Geladi P (1987) Principal Componet Analysis. ChemomIntell Lab Syst 2: 37-52. https://doi.org/10.1016/0169-7439(87)80084-9.

Jolliffe I (2005) Principal Component Analysis. Encycl Stat Behav Sci (American Cancer Society). https://doi.org/10.1002/0470013192.bsa501.

Rodrigues DW, Muller AFF, Bonomini TJ (2020) Chemical variability of Allamanda cathartica L. flowers assessed by multivariate data analysis. Quimica Nova, 43: 201. https://doi.org/10.21577/0100-4042.20170467. 